\title{
Home visits reduce the number of hazards for childhood home injuries in Karachi, Pakistan: a randomized controlled trial
}

\author{
Rifat Rehmani • John C. LeBlanc
}

Received: 21 January 2010 /Accepted: 6 September 2010/Published online: 7 December 2010

(C) The Author(s) 2010

\begin{abstract}
Background Although unintentional injuries are major causes of morbidity and mortality in less developed countries, they have received scant attention, and injury prevention policies and programs have just begun to be addressed systemically.

Aims To reduce hazards associated with home injuries due to falls and ingestions through an injury prevention program administered by home visitors.

Methods Non-blinded randomized controlled trial design of two interventions where one branch of the study group served as the control for the other in an urban neighborhood in Karachi, Pakistan. The study participants included 340 families with at least one child aged 3 years or less, discharged home from the Emergency Department following a visit for any reason other than an injury. The interventions included: (1) counseling to reduce falls; (2) counseling to reduce poisoning and choking. The primary outcome measure for each intervention was the relative risk of change in the home status from "unsafe" to "safe" after the intervention.

Results There were 170 families in the fall prevention and 170 families in the ingestion prevention branch of the study.
\end{abstract}

The views expressed in this paper are those of the author(s) and not those of the editors, editorial board or publisher.

R. Rehmani $(\bowtie)$

Department of Emergency Medicine, King Abdul Aziz Hospital,

P.O. Box 2477, Al-hasa 31982, Kingdom of Saudi Arabia

e-mail: rifatrehmani@hotmail.com

J. C. LeBlanc

Departments of Pediatrics, Psychiatry, Community Health and Epidemiology, Dalhousie University and the IWK Health Centre, 5850 University Avenue,

Halifax, Nova Scotia B3K 6R8, Canada
The percentage of homes deemed "safe" in which the families had received fall intervention counseling was $13.5 \%$ compared to $3.5 \%$ in the control group (relative risk $3.8 ; 95 \% \mathrm{CI}: 1.5$ to $10.0 ; \mathrm{p}=0.002)$, whereas the percentage of homes deemed "safe" in which the families had received the ingestions intervention counseling was $18.8 \%$ compared to $2.4 \%$ in the control group (relative risk 7.8; $95 \%$ CI: 2.4 to $25.3 ; \mathrm{p}<0.001$ ). Effectiveness did not depend on education or the socioeconomic status of the study participants. The mean number of fall hazards was reduced from 3.1 at baseline to 2.4 in the fall intervention counseling group, and the mean number of ingestion hazards decreased from 2.3 to 1.9 . $(\mathrm{p}<0.001)$.

Conclusions Our study demonstrates the effectiveness of an educational intervention aimed at improving the home safety practices of families with young children.

Keywords Home visits · Childhood injuries · Hazards · Randomized controlled trial $\cdot$ Pakistan

\section{Introduction}

Although unintentional injuries are major causes of morbidity and mortality in less developed countries [14], they have received scant attention [5, 6], and injury prevention policies and programs have just begun to be addressed systemically [7]. In Pakistan, 22\% of emergency room visits are injury-related [8], and a recent case series revealed that a large number of injuries to Pakistani children occur at home [9]. There is agreement that effective prevention programs should incorporate the three Es: (1) education, to influence behavior or raise awareness of injury risk, e.g., teach parents about childhood injuries; (2) engineering, to design devices in order to reduce their 
risk of injury, e.g., installing automobile air bags or reducing the temperature of household water heaters; (3) enforcement through legal regulation or sanctions, e.g., bicycle helmet laws, to prevent behavior likely to increase the risk of injury. Home visitation has been championed as an effective strategy that promotes the reduction of household hazards as it incorporates the tenets of education, engineering, and enforcement, and targets the hazards in the home that are likely to cause children to sustain injuries [10].

Concerning the risk of falls, the following hazards were identified and studied: no stair gate, presence of a baby walker, and windows opening easily in the living room and the child's bedroom. Similarly, for the ingestion risk, the following hazards were identified and studied: poisonous products in the bathroom and living room, and hazards on floor in the living room and child's bedroom. In developed countries, home visiting programs aimed at addressing injury prevention have led to a $25 \%$ reduction in the number of hazards in households that received home visits compared to households that did not [11]. The effectiveness of home visitation programs in Pakistan is unknown, and we found a few recently published articles indicating the effectiveness of similar programs in reducing targeted hazards in less developed countries $[12,13]$. We therefore undertook a randomized controlled trial to assess the impact of home visits on reducing the number of hazards for home injuries in young children who reside in Pakistan. A recent retrospective study from our ED confirmed that falls and ingestion are the two most common childhood injuries presenting to the department [14]. It also revealed that most childhood injuries occurred at home, falls being the most common mechanism of injury. Falling while running and/or playing accounted for $80 \%$, whereas falling from low heights (less than $1 \mathrm{~m}$ ) accounted for $20 \%$. For ingestion injuries, inedible items were more frequently the cause than edible items. We therefore focused on falls and ingestions, the two most common injuries in children presenting to the emergency department (ED) of Aga Khan University Hospital (AKUH).

We hypothesized that homes with children aged 3 and under in which the families had received injury prevention counseling at home would be safer than those not visited. The two intervention arms of this study allowed us to examine the effectiveness of counseling to reduce falls and counseling to reduce poisoning and choking. The principal objective was to measure the number of homes in which all specified hazards were removed from baseline to 6 months following the initial home visit. The secondary objectives were to examine the effect of the program on parental injury awareness and knowledge, and to assess the feasibility and acceptability of home safety inspection and education by home visitors.

\section{Methodology}

\section{Study participants}

The study was conducted at the Aga Khan University Hospital (AKUH), a 550-bed acute care urban center with about 12,000 pediatric ED visits annually. Inclusion criteria were: (1) families with at least one child aged 3 years old or younger discharged home from the ED following a visit for any reason other than an injury, (2) English or Urduspeaking, and (3) residing within 45-min driving distance from the hospital.

Children who presented with an injury were excluded in case the event had sensitized them to the importance of preventing injuries.

Study group and randomization

This was a non-blinded randomized controlled trial design in which one branch of the study group (injury prevention vs. ingestion prevention) served as the control for the other. This ensured that both groups received an intervention of potentially equal benefit. Parents of children up to 3 years who agreed to participate in the trial were randomly allocated to either group 1 (falls) or group 2 (ingestions: poisoning and choking). Parents in group 1 received falls safety and prevention counseling only; parents in group 2 received ingestion safety and prevention counseling only. The attending pediatrician introduced the study to parents of all eligible children at the time of discharge. Eligible families were formally approached within $24 \mathrm{~h}$ by the study coordinator and invited to participate in the trial. Simple randomization was done using a random number generator. The research assistant ensured that appropriate interventions were carried out depending on the group to which the participants were allocated.

\section{Sample size}

For power calculations, we assumed a common baseline rate of $12 \%$ of homes having no specified hazards for falls or for ingestions, and aimed to detect an intervention effect of at least doubling of the proportion of safe homes. A sample size of 142 homes per condition would yield $80 \%$ power with a type 1 error rate of 0.05 . To account for attrition, we recruited 170 participants per condition.

Intervention

Three men and three women were trained to undertake the home visits and were audited by the study coordinator at random visits. The research instruments consisted of a 
questionnaire measuring parental knowledge, attitudes, and behavior (KAB questionnaire), and a child safety checklist, an observational tool measuring the presence of hazards in the home. Research assistants administered the questionnaire after which $\mathrm{s} /$ he inspected the home for hazards in the presence of the family. The family was then assigned to either the falls or poisoning/ingestion intervention branches of the study. Families then received a 15-min education session in which the research assistant reviewed relevant fall or ingestion hazards, including revisiting problem areas in the dwelling and offering potential solutions to eliminate said hazards. The research assistant immediately informed the family of any obvious and serious hazards (e.g., easy access to open fire or no barrier to prevent falls). A followup telephone call was made 3 months later in which the parents were asked about safety enhancements made since the home visit. The second and final home visit was conducted 6 months after the first one, during which time home safety was reassessed followed by querying the family regarding safety issues for which the family served as a control.

The KAB questionnaire consists of ten questions that elicited the subject's general knowledge about homerelated injuries. For each question, each participant had to choose a number from 1-10: 1 , not at all serious to 10 , very serious. Hazards were classified as risk factors for falls, poisoning, suffocation, and fires/burns, and were measured as being present or absent. All instruments had been used in previous published studies [15]. The instruments were translated into Urdu and tested in a pilot program. A variable representing the "total number of hazards" was constructed by counting the number of "unsafe" practices in each home with respect to falls and with respect to ingestions. Each variable had a maximum score of 4 . For the fall risk, households were assigned 1 point for no stair gate, presence of a baby walker, and window openings exceeding $15 \mathrm{~cm}$ in the living room and/ or the child's bedroom. For ingestion risk, households were assigned 1 point for poisons (drugs and chemicals) not locked away in the bathroom or the kitchen, and choking hazards (any toy, food, or small object less than 1 $3 / 4$ inches in diameter, which can be a choking hazard) on the floor in the living room or in the child's bedroom. The four safety practices were assessed by home observation at baseline and follow-up.

\section{Study outcomes}

The primary outcome measures were the relative risks of houses that changed from "unsafe" to "safe" after the intervention, since this was done for the control and intervention groups, respectively. A house was considered "safe" if all items scored to 0 , the rationale being that a house was unsafe if even one hazard was present. A change from unsafe to safe was recorded if a home with at least one hazard at baseline had no hazards at follow-up. Homes were evaluated separately for falls and for ingestions/ poisonings. Knowledge, Attitude, and Behavior (KAB) scores were calculated for both groups.

\section{Statistical analysis}

We collected descriptive statistics for the two groups and analyzed data on an intention-to-treat basis. We compared the two intervention groups with their corresponding control groups using t-tests and chi-square statistics. Logistic regression was used to check for effect modification by covariates [mother's age and education, socioeconomic status, mother's age at first pregnancy, presence of male sibling younger than 3 (because of the perceived preference given to male children, their homes may be safer), and number of siblings].

\section{Ethics}

Permission to conduct the study was given by both the Dalhousie University Research Ethics Board (Halifax, NS, Canada) and Aga Khan University's Ethics Committee (Karachi, Pakistan).

\section{Results}

We recruited 340 families in January 2004 of whom 170 were randomized to receive fall prevention counseling (group 1) and 170 to ingestion safety counseling (group 2).

Follow-up was completed in July 2004. Figure 1 outlines the flow of participants from randomization to the last follow-up. In total, 304 (90\%) completed 6 months of follow-up, with a similar number lost to follow-up in the two study groups. The only reason for dropout was loss to follow-up. Baseline characteristics between the two randomized groups are presented in Table 1. The mean age of children was 26 months in both study groups, with males comprising about two-thirds in each group (Table 1). Mothers in both branches of the study had similar mean years of education and mean age at which they had their first child (26 years). The frequency of safety hazards observed during the initial home visit is shown in Table 2. The safety hazards were evenly distributed in the two branches of the study. Almost $90 \%$ of homes had stairs that were not protected by a stair gate or a door, and $48 \%$ of the sampled homes had a baby walker in their home. There was a high prevalence $(75 \%)$ of proper storage of poisons in homes. 
Fig. 1 Flow diagram of study design

\section{Flow diagram of study design}

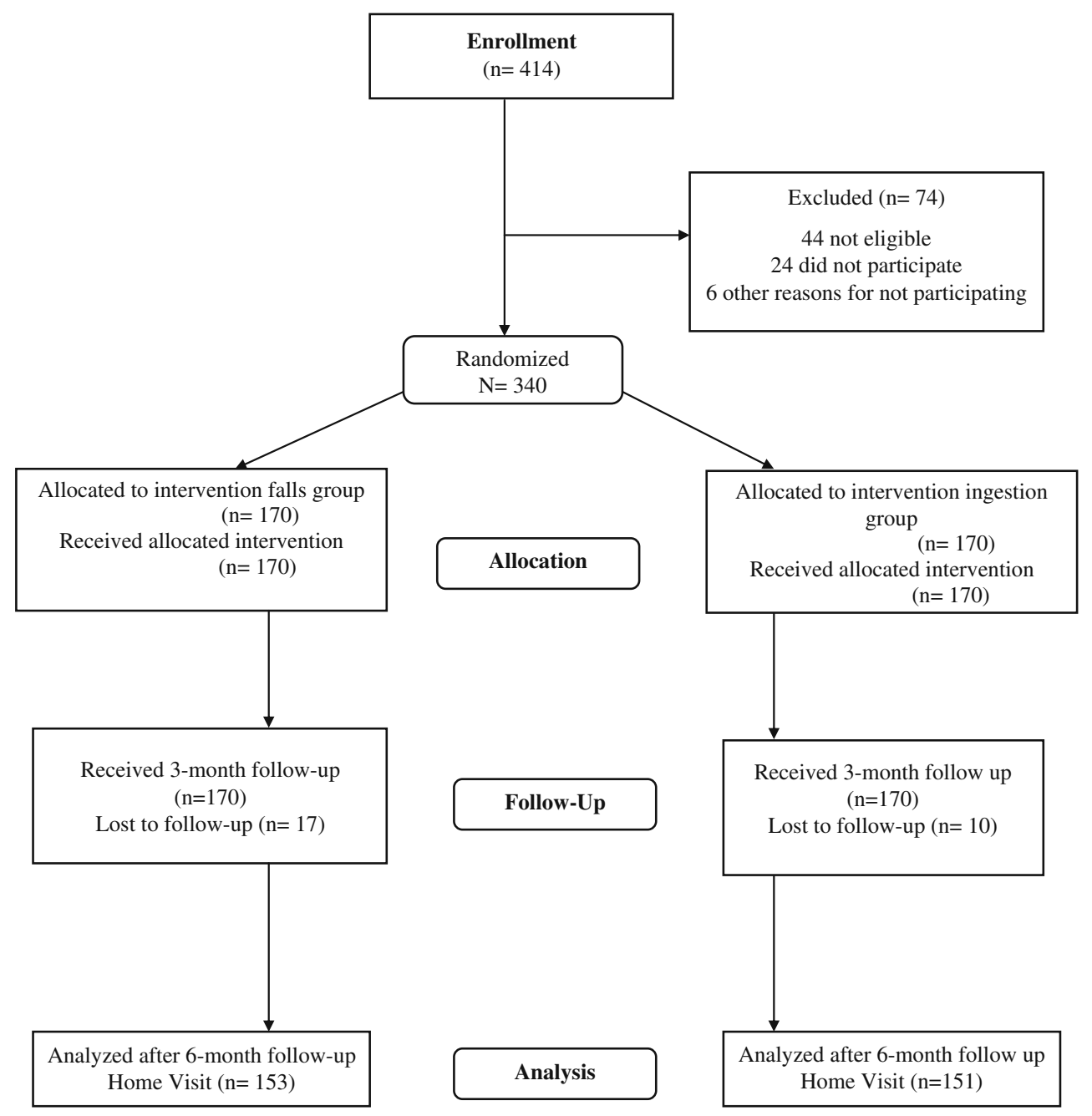

\section{Effect of intervention}

Of 141 intervention homes deemed unsafe for falls at baseline, 19 became safe after the intervention (T2) compared to 5 out of 142 in the control group for a relative risk of 3.8 (95\% CI: 1.5 to $10.0 ; p=0.002)$ (Table 3). Of 128 homes unsafe for ingestions at baseline, 24 became safe after the intervention (T2) as compared to 3 (out of $125)$ in the control group for a relative risk of $7.8(95 \% \mathrm{CI}$ : 2.4 to $25.3 ; \mathrm{p}<0.001$ ) (Table 4 ).

There was also significant improvement in the total number of hazards in the intervention groups from baseline. The mean number of fall hazards reduced from 3.1 at baseline to 2.4 in the falls intervention group, and the mean

Table 1 Participant demographics

\begin{tabular}{llll}
\hline & Fall intervention $(\mathrm{n}=170)$ & Ingestion intervention $(\mathrm{n}=170)$ & Total $(\mathrm{n}=340)$ \\
\hline Male, $\mathrm{n}(\%)$ & $119(70.0 \%)$ & $108(63.5 \%)$ & $227(66.8 \%)$ \\
Child's age in months & $26.3 \pm 9.6$ & $25.2 \pm 10.1$ & $25.8 \pm 9.8$ \\
Mother's age in years & $31.0 \pm 3.5$ & $30.6 \pm 3.0$ & $30.8 \pm 3.2$ \\
Age mother had first child & $25.5 \pm 3.1$ & $25.8 \pm 2.6$ & $25.7 \pm 2.9$ \\
Mother's years of education & $11.2 \pm 3.0$ & $10.8 \pm 2.6$ & $11.2 \pm 2.8$ \\
Number of siblings & $2.5 \pm 1.1$ & $2.3 \pm 1.1$ & $2.4 \pm 1.1$ \\
\hline
\end{tabular}

*Values are means unless otherwise stated 
Table 2 Safety hazards observed during the initial home visit

\begin{tabular}{llll}
\hline Safety hazards & $\begin{array}{l}\text { Fall group } \\
(\mathrm{n}=170) \\
\text { Number } \\
(\%) \text { of } \\
\text { homes }\end{array}$ & $\begin{array}{l}\text { Ingestion group } \\
(\mathrm{n}=170)\end{array}$ & $\mathrm{p}$ value \\
\hline $\begin{array}{l}\text { Stair gates } \\
\text { Baby walkers }\end{array}$ & $15(8.8)$ & $9(5.3)$ & 0.15 \\
$\begin{array}{l}\text { Windows open } \\
\text { less than 15 cm }\end{array}$ & $5(3.0)$ & $16(9.4)$ & 0.08 \\
$\begin{array}{c}\text { Poisons kept } \\
\text { locked or latched }\end{array}$ & $134(79)$ & $127(75)$ & 0.01 \\
$\begin{array}{c}\text { Small objects } \\
\text { on the floor }\end{array}$ & $129(76)$ & $141(84)$ & 0.22 \\
\hline
\end{tabular}

number of ingestion hazards decreased from 2.3 to 1.9. The intervention reduced the hazards score in both the fall and poisoning groups, as compared to no change for the control groups, as shown in Table 5, thus demonstrating the specific effectiveness of the intervention and the absence of confounders.

When analyzing only the fall intervention households that had at least one fall hazard at baseline, $58 \%$ of those households reduced the number of hazards by one or more.

Correspondingly, $66 \%$ of households with at least one ingestion hazard that had received the ingestion intervention reduced the number of hazards by at least one.

Injury knowledge, awareness, and behaviors

The KAB scores of the two groups were comparable in terms of socioeconomic status, and injury awareness and knowledge. Mean scores for the perception of injury preventability were 3.0 and 2.5 (out of 10) for the fall and ingestion groups, respectively, while the mean scores for perceived control over decreasing injury risk were 2.7 and 2.2 (out of 10) for the fall and ingestion groups.

Multivariate logistic regression analysis showed that demographic characteristics did not modify the effect of each intervention.

Table 3 Impact of fall interventions on homes with at least one fall hazard at baseline

\begin{tabular}{|c|c|c|c|c|c|c|}
\hline & \multicolumn{2}{|c|}{ Intervention } & \multicolumn{2}{|c|}{ Control } & \multirow[t]{2}{*}{ RR } & \multirow[t]{2}{*}{$(95 \% \mathrm{CI})^{*}$} \\
\hline & \multicolumn{4}{|c|}{ N (\%) } & & \\
\hline Safe at $\mathrm{T} 2$ & 19 & (13.5) & 5 & (3.5) & & \\
\hline Unsafe at $\mathrm{T} 2$ & 122 & $(86.5)$ & 137 & $(96.5)$ & 3.8 & $(1.5,10.0)$ \\
\hline Unsafe at $\mathrm{T} 1$ & 141 & & 142 & & & \\
\hline
\end{tabular}

Table 4 Impact of ingestion interventions on homes with at least one ingestion hazard at baseline

\begin{tabular}{|c|c|c|c|c|c|c|}
\hline & \multicolumn{2}{|c|}{ Intervention } & \multicolumn{2}{|c|}{ Control } & \multirow[t]{2}{*}{$\mathrm{RR}$} & \multirow[t]{2}{*}{$(95 \% \mathrm{CI})^{*}$} \\
\hline & $\mathrm{N}(\%$ & & & & & \\
\hline Safe at T2 & 24 & $(18.8)$ & 3 & (2.4) & & \\
\hline Unsafe at $\mathrm{T} 2$ & 104 & $(81.2)$ & 122 & $(97.6)$ & 7.8 & $(2.4,25.3)$ \\
\hline Unsafe at $\mathrm{T} 1$ & 128 & & 125 & & & \\
\hline
\end{tabular}

\section{Discussion}

This trial demonstrated that Pakistani home visits focusing on reducing injury hazards had a large impact on urban families with relatively high levels of education. Moreover, we did not find the home visits difficult to implement, and we were successful in gaining access to $88 \%$ of the homes. The result of the randomized controlled trial (RCT) indicated that the intervention was effective in reducing targeted hazards in a low-income South African setting. The two systematic reviews concluded that home visits can substantially reduce rates of unintentional injuries, particularly in families at increased risk of injuries at home [16, 17]. A Canadian study examining the effectiveness of a home visit to improve home safety found that significant safety modifications only occurred in the number of homes having hot water exceeding $54^{\circ} \mathrm{C}$ or the absence of a smoke detector [18]. We hypothesized that the difference in Pakistan, as compared to the Canadian study, probably relates to a cultural difference, since health advice is often adhered to by Pakistani people. Other possible reasons are differences in education or income between less developed and developed countries. However, logistic regression analysis demonstrated that the intervention was just as effective for lower income participants with little education as for higher income participants with more education.

Previous intervention studies have not shown consistently positive results in the prevention of injuries sustained in the home. In some studies, primary care-based education

Table 5 Number of hazards pre- and post-intervention

\begin{tabular}{llll}
\hline & $\begin{array}{l}\text { Baseline hazard } \\
\text { score; mean (SD) }\end{array}$ & $\begin{array}{l}\text { Post-intervention } \\
\text { hazard score; } \\
\text { mean (SD) }\end{array}$ & $\begin{array}{l}\mathrm{P} \\
\text { value }\end{array}$ \\
\hline $\begin{array}{l}\text { Fall group } \\
\text { Intervention }\end{array}$ & $3.1(0.7)$ & $2.4(0.8)$ & $<0.001$ \\
$\begin{array}{l}\text { Control } \\
\text { Ingestion group }\end{array}$ & $3.0(0.7)$ & $2.9(0.7)$ & 0.3 \\
$\begin{array}{l}\text { Intervention } \\
\text { Control }\end{array}$ & $2.3(1.2)$ & $1.9(1.3)$ & $<0.001$ \\
\hline
\end{tabular}


had a limited effect on improving home safety [9]. Some authors have suggested that a limiting factor may be the broad scope of many interventions [19]. Interventions might be more effective if they are simpler and more focused, as in this study.

Pakistan does not have legislation requiring safety caps on prescriptions. Fortunately, about $75 \%$ of households in our study stored poisons in locked cabinets. Mandatory safety caps on bottles would likely be beneficial for the $25 \%$ of households that did not store medications in locked cabinets.

In our study, the injury hazards were evenly distributed among both fall and poisoning groups, except for windows opening less than $15 \mathrm{~cm}$. This is probably because they were in newly constructed apartments that are compliant with building codes (Table 2). Parents' knowledge about fall hazards was generally low. This, along with defining barriers and exploring hazard reduction opportunities to eliminate them, needs to be investigated (e.g., difficulty in obtaining stair gates and perceived benefits of using baby walkers).

There are a few limitations that can be addressed in future studies. This intervention in an urban, fairly welleducated population may not be generalizable to rural settings or populations with low levels of literacy. Another limitation is that we have measured home injury hazards and not the occurrence of injuries. However, based on studies that relate the presence of hazards with an increased risk of injury, it is reasonable to use a proxy measure, and indeed this is the only feasible approach without requiring the thousands of research participants needed to demonstrate a reduction in injuries.

Our study demonstrates the effectiveness of an educational intervention program aimed at improving the home safety practices of families with young children. Concerning houses that were deemed "unsafe" in regard to falls at baseline, the number of households deemed "safe" at follow-up had about a four-fold increase compared to the control group. Similarly, for houses that were deemed "unsafe" with regard to ingestion at baseline, the number of households deemed "safe" at follow-up had increased about eight-fold compared to the control group. Despite these impressive improvements, the majority of households in both groups still had at least one hazard for falls or for ingestions. This implies a need to refine the intervention or combine it with other strategies that will make homes safer. In addtion, our results need to be replicated in a rural setting with lower levels of education and low SES, and possibly a difference in the number and type of home hazards.

Recognizing that a "one size fits all" approach to interventions does not work, it is also recommended that successful and promising home-visitation programs be tested across different communities and with different groups of home visitors to determine their utility and impact across varying conditions. This intervention is feasible in Pakistan because of the existence of female health workers, 75,000 women whose main focus is delivering primary health care at the village or neighborhood level. Injury prevention education could easily be implemented as part of home visits. This should be tested in a randomized controlled trial since it is possible that the injury prevention messages may be diluted by the other messages delivered in a home visit, and the impact found in this trial may be lessened.

Home visits were feasible and acceptable to the families, and there was a statistically significant increase in their knowledge, awareness, and behavior. Further work is needed to determine the long-term impact of this intervention and its extension to other settings such as villages and rural areas.

Funding A grant was provided by the University Research Council of Aga Khan University, Pakistan.

\section{Conflicts of interest None.}

\section{What is already known on this topic?}

- In developed countries home visiting programs for injury prevention have led to a $25 \%$ reduction in the number of hazards in households that received home visits compared to households that did not.

\section{What this study adds}

- This trial has demonstrated that in Pakistan, a less developed country, home visitations focused on reducing injury hazards had a large impact on urban families.

- Interventions might be more effective if they are simple and more targeted.

- Home visits were feasible and acceptable to the families.

\section{References}

1. Krug EG, Sharma GK, Lozano R (2000) The global burden of injuries. Am J Public Health 90:523-526

2. Sharma AK, Sarin YK, Manocha S et al (1993) Patterns of childhood trauma: Indian perspective. Indian Pediatr 30:57-60

3. Deen JL, Vos T, Huttly SR et al (1999) Injuries and noncommunicable diseases: emerging health problems of children in developing countries. Bull World Health Organ 77:518-524

4. Paden M, McGee K, Krug E (Eds) (2002). Injury: a leading cause of the global burden of disease, 2000. Geneva. World Health Organization

5. Bartlett SN (2002) The problem of children's injuries in lowincome countries: a review. Health Policy Plann 17:1-13

6. Swart L, Seedat M (2001) An epidemiological study of injury in a low socioeconomic context: implications for prevention. Inj Control Saf Promot 8:241-249 
7. Peden M, Scurfield R, Sleet D, Mohan D, Hyder AA, Jarawan E, Mathers C (eds) (2004) World report on road traffic injury prevention, 1 st edn. World Health Organization, Geneva Switzerland

8. Ghaffar A, Siddiqui S, Shahab S, Hyder A (1999) National injury survey of Pakistan. Injury Research Center, Ministry of Health, Government of Pakistan, Islamabad

9. Razzak JA, Luby SP, Laflamme L, Chotani H (2004) Injuries among children in Karachi, Pakistan-what, where and how. Public Health 118:114-120

10. Klassen TP, MacKay JM, Moher D, Walker A, Jones AL (2000) Community-based injury prevention interventions. The Future of Children 10 (1): 83-110

11. Kendrick D, Coupland C, Mulvaney C et al (2007) Home safety education and provision of safety equipment for injury prevention. Cochrane Database Syst Rev 1:CD005014

12. Swart L, van Niekerk A, Seedat M, Jordaan E (2008) Paraprofessional home visitation program to prevent childhood unintentional injuries in low-income communities: a cluster randomized controlled trial. Inj Prev 14:164-169

13. Odendaal W, van Niekerk A, Jordaan E, Seedat M (2009) The impact of a home visitation program on household hazards associated with unintentional childhood injuries: a randomized controlled trial. Accid Anal Prev 41(1):183-190

14. Rehmani R (2008) Epidemiology of childhood injuries seen at an emergency department. J Pak Med Assoc 58:114-118
15. LeBlanc JC, Pless IB, King WJ, Bawden H, Bernard-Bonnin A, Klassen TP et al (2006) Home safety measures and the risk of unintentional injury in young children: a multi-centre case-control study. CMAJ 175:883-887

16. Kendrick D, Barlow J, Hampshire A, Polnay L, Stewart-Brown S (2007) Parenting interventions for the prevention of unintentional injuries in childhood. Cochrane Database Syst Rev 4:CD006020

17. Kendrick D, Elkan R, Hewitt M, Dewey M, Blair M, Robinson J, Williams D, Brummell K (2000) Does home visiting improve parenting and the quality of the home environment? A systematic review and meta analysis. Arch Dis Child 82:443-451

18. King WJ, Klassen TP, LeBlanc J, Bernard-Bonnin AC, Robitaille Y, Pham B et al (2000) The effectiveness of a home visit to prevent childhood injury. Pediatrics 108:382-388

19. Cohen LR, Runyan CV, Downs SM, Bowling JM (1997) Pediatric injury prevention counseling priorities. Pediatrics 99:704-710

Dr. Rifat Rehmani is an epidemiologist and emergency physician by training, and presently working in the Department of Emergency Medicine at the King Abdul Aziz National Guard Hospital (KAH), AlAhsa, Kingdom of Saudi Arabia. In addition to emergency medicine and epidemiology, his specialty interests include trauma and injury prevention, disaster medicine, resuscitation, and pain management. 